\title{
The Effect of Pregabalin on Chemokines in Patients with Neuropathic Pain
}

\author{
SHUWEN DENG AND HONGXING XIA ${ }^{1 *}$ \\ Department of Pain, ${ }^{1}$ Department of Gastrointestinal Surgery, Affiliated Nanhua Hospital, University of South China, Hengyang \\ 421002, Hunan Province, China
}

Deng et al.: Effect of Pregabalin in Neuropathic Pain Patients

\begin{abstract}
We attempt to discuss the effect of pregabalin on chemokines and clinical efficacy in neuropathic pain patients. We selected 40 patients with neuropathic pain from December 2018 to December 2020 as research objects and divided them into two groups, one is observation group (20 cases) and the other is control group (20 cases) randomly. Treated observation group with pregabalin and treated control group with gabapentin. Extracted cerebrospinal fluid from the patients and detected its concentration levels of $\mathrm{C}-\mathrm{X} 3-\mathrm{C}$ motif chemokine ligand 1, C-X-C motif chemokine ligand 1, C-X-C motif chemokine ligand 8 and $\mathrm{C}-\mathrm{C}$ motif chemokine ligand 2 of both groups, compared the concentration levels, the adverse drug reactions and clinical effects of both groups. After treatment, the concentration levels of cerebrospinal fluid chemokines C-X3-C motif chemokine ligand 1, C-X-C motif chemokine ligand 1, C-X-C motif chemokine ligand 8 and $\mathrm{C}-\mathrm{C}$ motif chemokine ligand 2 decreased in both groups. Contrast control groups, observation group decreased more obvious $(p<0.05)$ and observation group had higher clinical remission rate than the other $(p<0.05)$, both of which had statistical significance. For patients with neuropathic pain, pregabalin treatment can reduce the chemokines in cerebrospinal fluid of patients and significantly relieve patient's pain.
\end{abstract}

Key words: Pregabalin, neuropathic pain, chemokines, clinical effective rate

In 2018, the neuropathic pain group redefined neuropathic pain as, it was a consequence of pain which was caused by injury or disease directly affecting the somatosensory system ${ }^{[1]}$. Its prevalence accounts for $9.8 \%$ of the population, accounting for about one-third of adult chronic pain patients ${ }^{[2]}$. There are many reasons for neuropathic pain and based on causes of nerve injury, its classification was done. Common causes include diabetes (Painful Diabetic Neuropathy (PDN), herpes zoster (Postherpetic Neuralgia (PHN)), amputation (stump and phantom limb pain), surgery or trauma, stroke or spinal cord injury, trigeminal neuralgia and neuropathic pain caused by Human Immunodeficiency Virus (HIV) infection and unknown causes ${ }^{[3]}$.

Due to the current lack of understanding of the pathogenesis involved in neuropathic pain, the management of neuropathic pain remains a major clinical challenge. Most of the current treatment drugs are drugs against neuropathic pain, such as antidepressants, opioids, anticonvulsants, N-methyl D-aspartate (NMDA) receptor agonists, sodium channel blockers and cannabinoid receptor agonists. Most of the effects of drugs are difficult to achieve satisfactory results and they are often accompanied by obvious side effects ${ }^{[4]}$. Among them, pregabalin is a drug approved for the treatment of neurological diseases and gabapentin drugs exert their analgesic effect through the antagonistic activity of binding with Alpha-2-delta subunits on voltage-gated $\mathrm{Ca}^{2+}$ channels. It could serve as the first-line drug therapy for neuropathic pain ${ }^{[5,6]}$.

Chemokines are low-molecular weight proteins that transmit signals through 7 transmembrane receptors connected by G-protein and regulate the transport of leukocytes to lymphoid organs or inflammation sites by inducing leukocytes to migrate to the source of chemokines. Chemokines can be divided into inflammatory chemokines and steady-state chemokines ${ }^{[7]}$. Many clinical studies have proved that pro-inflammatory cytokines and chemokines expressions in the cerebrospinal fluid of neuropathic pain patient's change and some chemokines such as C-X3-C Motif Chemokine Ligand 1 (CX3CL1), C-X-C Motif Chemokine Ligand 1 (CXCL1), C-X-C Motif Chemokine Ligand 8 (CXCL8), C-C Motif Chemokine Ligand 7 (CCL7) and C-C Motif Chemokine Ligand 2 (CCL2) have important effect on pain regulation ${ }^{[8]}$.

*Address for correspondence

E-mail:8076478@qq.com 
However, whether pregabalin affects chemokines in patients with neuropathic pain is not clear at present. This article explores the effect of pregabalin on chemokines in patients with neuropathic pain and offers the theoretical evidence for neuropathic pain clinical treatment.

\section{MATERIALS AND METHODS}

\section{General information:}

Selected 40 neuropathic pain patients from December 2018 to December 2020 as research subjects and divided them into observation group (20 cases) and control group (20 cases) randomly. Exclusion criteria are: Patients who took other neuropathic pain medications within $1 \mathrm{w}$ before treatment; patients with mental disorders or communication disorders; patients were unwilling to take medications.

\section{Treatment methods:}

Observation group: Use initial dose of pregabalin 150 $\mathrm{mg} / \mathrm{d}$, according to safety and tolerability, it could be raised to $300 \mathrm{mg} / \mathrm{d}$ within a week and the maximum was $600 \mathrm{mg} / \mathrm{d}$.

Control group: Gabapentin $900 \mathrm{mg} / \mathrm{d}$ was taken orally. During the treatment period, the patient could take tramadol hydrochloride sustained-release tablets 50$100 \mathrm{mg}$ orally when the pain was unbearable and allow the use of antidepressants, neurotrophic drugs and other drugs.

\section{Observation indicators:}

On the $1^{\text {st }}$ and $7^{\text {th }} \mathrm{d}$ of admission, $2 \mathrm{ml}$ of cerebrospinal fluid was collected by lumbar puncture and the concentrations of chemokines CX3CL1, CXCL1, CXCL8 and CCL2 in the cerebrospinal fluid of the four groups of patients were detected before and after treatment.

\section{Curative effect evaluation index:}

The Numerical Rating Scale (NRS) was used to evaluate the pain. NRS is a self-report scale. Adopted Visual Analogue Scale (VAS) score to test pain score ${ }^{[9]}$, VAS score ranges from 0 (no pain) to 10 (most painful), the higher the score, the more serious the pain. Among them, VAS 0 represented painless, VAS 1 3 represented mild pain, VAS $4 \sim 6$ represented moderate pain and VAS 7 10 represented severe pain. Complete Relief (CR) and Partial Relief (PR) meant that the patient had no pain or obvious pain relief and the clinical effective rate $=\mathrm{CR}+\mathrm{PR}$.

\section{Statistical methods:}

Adopted Statistical Package for the Social Sciences (SPSS) 26.0 to process data and use mean \pm standard deviation $(\overline{\mathrm{x}} \pm \mathrm{s})$ to indicate measurement data, contrast both groups by independent sample $t$ test. The comparison between the groups treated is done using Wilcoxon signed rank test and chi-square test for qualitative data, $\mathrm{p}<0.05$ indicated that this difference showed statistical significance.

\section{RESULTS AND DISCUSSION}

The baseline data of both groups were compared. The average age of observation group was $(56.2 \pm 2.8)$ y old, most of the disease sites are in the chest and back, it had 8 cases, the VAS score was $8.1 \pm 1.5$; The average age of control group was $(57.0 \pm 2.1)$ y old, the diseased parts were distributed in the head, neck, chest and back, and the VAS score was $8.4 \pm 1.3$. The differences of both groups baseline data had no statistical significance ( $>0.05)$ (Table 1).

The cerebrospinal fluid chemokines before treatment were compared. Comparing the concentrations of CX3CL1, CXCL1, CXCL8 and CCL2 in the cerebrospinal fluid of both groups of patients before treatment, the divergence possessed no statistical significance $(\mathrm{p}>0.05)$ (Table 2$)$.

The cerebrospinal fluid chemokines after treatment were compared. After pregabalin treatment, the concentrations of CX3CL1, CXCL1, CXCL8 and CCL2 in the cerebrospinal fluid of the two groups of patients decreased after treatment, observation group chemokines decreased more remarkably, which was statistically significant $(\mathrm{p}<0.05)$ (Table 3 and fig. 1).

Drug side effect rate in both groups were observed. It possessed no statistically significant difference in drug side effect rate such as dizziness, allergic reactions, lower extremity edema and bradycardia of both groups (Table 4).

Clinical effective rate of both groups were compared. There were 16 patients under the condition complete remission and partial remission in observation group, with an effective rate of $80 \%$, but 11 patients under the condition complete remission and partial remission in control group, with an effective rate of $55 \%$. Contrast control group, observation group was remarkably higher. The difference of both groups was remarkably significant $(\mathrm{p}<0.05)($ Table 5). 
TABLE 1: BASELINE DATA OF BOTH GROUPS PATIENTS

\begin{tabular}{lcccc}
\hline & $\begin{array}{c}\text { Observation group } \\
(\mathrm{n}=\mathbf{2 0})\end{array}$ & Control group $(\mathrm{n}=\mathbf{2 0})$ & $\mathrm{t} / \mathrm{\chi}^{2}$ & $\mathrm{p}$ \\
\hline Age & $56.2 \pm 2.8$ & $57.0 \pm 2.1$ & -1.02 & 0.33 \\
Disease sites & & & & \\
Head and neck & 5 & 7 & 0.48 & 0.49 \\
Chest and back & 8 & 7 & 0.11 & 0.74 \\
Lower limbs & 7 & 6 & 0.11 & 0.73 \\
VAS & $8.1 \pm 1.5$ & $8.4 \pm 1.3$ & -0.67 & 0.52 \\
\hline
\end{tabular}

TABLE 2: CONTRAST CHEMOKINES OF BOTH GROUPS PATIENTS BEFORE TREATMENT

\begin{tabular}{lcccc}
\hline & $\begin{array}{c}\text { Observation group } \\
(\mathrm{n}=20)\end{array}$ & Control group $(\mathrm{n}=20)$ & $\mathrm{t}$ & $\mathrm{p}$ \\
\hline CX3CL1 $(\mathrm{ng} / \mathrm{ml})$ & $204.8 \pm 39.2$ & $206.9 \pm 35.9$ & -0.17 & 0.86 \\
CXCL1 $(\mathrm{pg} / \mathrm{ml})$ & $21.3 \pm 3.2$ & $22.4 \pm 4.5$ & -1.21 & 0.23 \\
CXCL8 $(\mathrm{pg} / \mathrm{ml})$ & $257.8 \pm 23.2$ & $249.8 \pm 24.6$ & 1.06 & 0.29 \\
CCL2 $(\mathrm{pg} / \mathrm{ml})$ & $230.5 \pm 20.1$ & $222.5 \pm 16.7$ & 1.36 & 0.17 \\
\hline
\end{tabular}

TABLE 3: COMPARISON OF CHEMOKINES OF BOTH GROUPS PATIENTS AFTER TREATMENT

\begin{tabular}{lcccc}
\hline & $\begin{array}{c}\text { Observation group } \\
(\mathbf{n}=20)\end{array}$ & Control group $(\mathbf{n = 2 0})$ & $\mathrm{t}$ & $\mathrm{p}$ \\
\hline CX3CL1 $(\mathrm{ng} / \mathrm{ml})$ & $116.2 \pm 19.2$ & $185.6 \pm 22.5$ & -10.24 & 0.0000 \\
CXCL1 $(\mathrm{pg} / \mathrm{ml})$ & $14.4 \pm 2.2$ & $17.6 \pm 3.5$ & -3.46 & 0.001 \\
CXCL8 $(\mathrm{pg} / \mathrm{ml})$ & $160.2 \pm 24.1$ & $193.5 \pm 31.5$ & -3.75 & 0.001 \\
CCL2 $(\mathrm{pg} / \mathrm{ml})$ & $155.8 \pm 34.1$ & $181.8 \pm 36.2$ & -2.33 & 0.02 \\
\hline
\end{tabular}

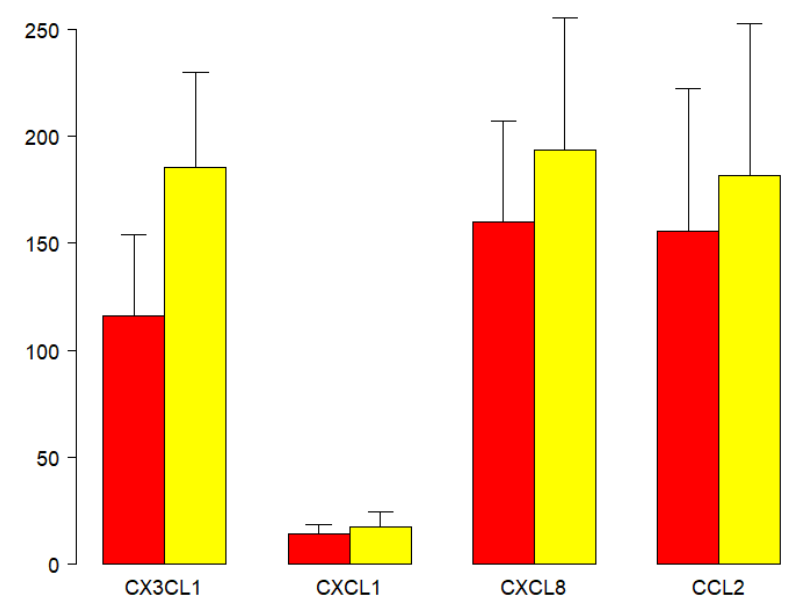

Fig. 1: Comparison of chemokines between the two groups after treatment,( $\square$ ) Intervention group; ( $\square$ ) Control group

TABLE 4: COMPARISON OF THE INCIDENCE OF ADVERSE DRUG REACTIONS OF BOTH GROUPS

\begin{tabular}{lcccc}
\hline & $\begin{array}{c}\text { Observation group } \\
(\mathrm{n}=\mathbf{2 0})\end{array}$ & Control group $(\mathrm{n}=\mathbf{2 0})$ & $\chi^{2}$ & $\mathrm{p}$ \\
\hline Dizziness & $1(5.0 \%)$ & $2(10.0 \%)$ & 0.36 & 0.54 \\
Allergic reaction & $0(0.0 \%)$ & $1(5.0 \%)$ & 1.03 & 0.31 \\
Lower extremity edema & $0(0.0 \%)$ & $1(5.0 \%)$ & 1.03 & 0.31 \\
Bradycardia & $1(0.0 \%)$ & $2(10.0 \%)$ & 0.36 & 0.54 \\
\hline
\end{tabular}


www.ijpsonline.com

TABLE 5: COMPARISON OF CLINICAL EFFICACY OF BOTH GROUPS

\begin{tabular}{lccccc}
\hline & $\begin{array}{c}\text { Complete } \\
\text { remission }\end{array}$ & Partial remission & Mild remission & Ineffectiveness & Total effective rate \\
\hline Observation group & $10(50 \%)$ & $6(30 \%)$ & $3(15 \%)$ & $1(5 \%)$ & $16(80 \%)$ \\
Control group & $7(35 \%)$ & $4(20 \%)$ & $6(30 \%)$ & $4(20 \%)$ & $11(55 \%)$ \\
$\chi^{2}$ & & & & & 8.46 \\
$\mathrm{p}$ & & & & & 0.001 \\
\hline
\end{tabular}

Neuropathic pain is a major health problem in today's society. It greatly leads to reduce the quality of life of patients ${ }^{[10]}$ and brings a major economic burden to the medical and health system and society ${ }^{[11]}$. Understanding the pathophysiological process and underlying molecular mechanisms of neuropathic pain will help to develop new therapies for neuropathic pain. Studies have proved that neuroinflammation and glial cells activation are one of the most important theories in pathogenesis of neuropathic pain. Microglia, as immune cells in Central Nervous System (CNS), performs a vital role in development and homeostasis of CNS and neuropathic pain occurring will activate microglia, it can initiate a series of signal cascades. These cascades can enhance neuronal excitability and synaptic plasticity, thereby releasing pro-inflammatory cytokines and chemokines and leading to the occurrence of neuropathic pain ${ }^{[12,13]}$.

Plenty of studies have proved that CCL2 and CCL7 and $\mathrm{C}-\mathrm{X}-\mathrm{C}$ Motif Chemokine Ligand 13 (CXCL13) interact with mediated neuron-glial cells in CNS interactions and cause neuropathic and inflammatory pain. In addition, CCL 2 and CCL 7 are common spinal microglia activators in neuropathic pain ${ }^{[12,14]}$ and it is often possible to suppress the growth of astrocytes by reducing the level of CCL 7 in the spinal cord. Previous studies have detected the levels of certain chemokines in serum or cerebrospinal fluid, such as the elevated levels of CCL2, CXCL1, C-X-C Motif Chemokine Ligand 12 (CXCL12) and CX3CL1 in the cerebrospinal fluid of chronic pain patients. It is very important to determine the chemokine expression profile in cerebrospinal fluid of chronic pain patients to reveal the relationship between chemokine levels and the severity of chronic pain. This study found that the chemokines of patients with neuropathic pain are generally increased, which is consistent with the above research conclusions.

Pregabalin is a Gamma Aminobutyric Acid (GABA) analog structure drug ${ }^{[15]}$, which can induce the release of calcium from nerve endings and inhibit the release of neurotransmitters such as glutamate, norepinephrine and substance $\mathrm{P}^{[5]}$. Due to its chemical structure 167 and drug properties, pregabalin is widely used for neuropathic pain treatment ${ }^{[10,16-18]}$. Salat et al. studied the analgesic, antioxidant, metabolic and toxic effects of pregabalin and concluded that pregabalin increased the pain threshold of tactile allodynia and thermal hyperalgesia, and was an effective analgesic and antiallodynia drug, had a good effect on neuropathic pain ${ }^{[19]}$. Mark et al. found that the analgesic effect of pregabalin was mediated by the Alpha-2-Delta-1 $(\alpha 2-\delta-1)$ subunit of the Voltage-Dependent Calcium Channel (VDCC), gene mutations could prevent pregabalin from binding to the $\alpha 2-\delta-1$ subunit, thereby to achieve the therapeutic effect. Pregabalin is currently one of the suggested first-line drugs for neuropathic pain treatment (except trigeminal neuralgia) and more completed clinical trials have proved its clear efficacy ${ }^{[20,21]}$. However, the effect of pregabalin on chemokines is unclear. This study shows that the chemokines of neuropathic pain patients treated with pregabalin are significantly reduced. We speculate that pregabalin joint $\alpha 2-\delta-1$ type protein of the P/Q VDCC and reduce central release of excitatory molecules, which may be one of the reasons for the reduction of chemokines.

Pregabalin treatment can significantly reduce the levels of cerebrospinal fluid chemokines CX3CL1, CXCL1, CXCL8 and CCL2 in patients with neuropathic pain and improve the clinical effective rate. It is worthy of clinical promotion.

\section{Conflict of interests:}

The authors declared no conflict of interest.

\section{REFERENCES}

1. Ren H, Jin H, Jia Z, Ji N, Luo F. Pulsed radiofrequency applied to the sciatic nerve improves neuropathic pain by downregulating the expression of calcitonin gene-related peptide in the dorsal root ganglion. Int J Med Sci 2018;15(2):153.

2. Tigerholm J, Poulsen AH, Andersen OK, Mørch CD. From perception threshold to ion channels-A computational study. Biophys J 2019;117(2):281-95.

3. Sierra S, Gupta A, Gomes I, Fowkes M, Ram A, Bobeck EN, et al. Targeting cannabinoid 1 and delta opioid receptor heteromers alleviates chemotherapy-induced neuropathic pain. ACS Pharmacol Transl Sci 2019;2(4):219-29. 
4. Shen JB, Neuropathic pain diagnosis and treatment expert group. Expert consensus on diagnosis and treatment of neuropathic pain. Chin J Intern Med 2009;(6):526-8.

5. Zhang XS, Ni JX. Application of pregabalin in controlling chronic pain. Chin J New Drugs 2008;17(16):1452-6.

6. Onakpoya IJ, Thomas ET, Lee JJ, Goldacre B, Heneghan CJ. Benefits and harms of pregabalin in the management of neuropathic pain: A rapid review and meta-analysis of randomised clinical trials. BMJ Open 2019;9(1):e023600.

7. Cassier PA, Treilleux I, Bachelot T, Ray-Coquard I, BendrissVermare N, Ménétrier-Caux C, et al. Prognostic value of the expression of C-Chemokine Receptor 6 and 7 and their ligands in non-metastatic breast cancer. BMC Cancer 2011;11(1):1-10.

8. Liang Y, Li XS, Yuan L, Meng CY. The related mechanism and research progress of CXCL1/CXCR2 and neuropathic pain. China Clin Pract Med 2019;10(1):72-4.

9. Haefeli M, Elfering A. Pain assessment. Eur Spine J 2006;15(1):S17-24.

10. Zhang Pan. Analysis of the effect of pregabalin on diabetic peripheral neuropathy. Orient Med Diet 2021;(3):120.

11. Grace PM, Hurley D, Barratt DT, Tsykin A, Watkins LR, Rolan PE, et al. Harnessing pain heterogeneity and RNA transcriptome to identify blood-based pain biomarkers: A novel correlational study design and bioinformatics approach in a graded chronic constriction injury model. J Neurochem 2012;122(5):976-94.

12. Li J, Deng G, Wang H, Yang M, Yang R, Li X, et al. Interleukin$1 \beta$ pre-treated bone marrow stromal cells alleviate neuropathic pain through CCL7-mediated inhibition of microglial activation in the spinal cord. Sci Rep 2017;7(1):1-5.

13. Zhao H, Alam A, Chen Q, A Eusman M, Pal A, Eguchi S, et al. The role of microglia in the pathobiology of neuropathic pain development: What do we know? $\mathrm{Br} \mathrm{J}$ Anaesth 2017;118(4):504-16.
14. Jiang Y, Chen N. Mechanism of CCL2/MCP-1 in its relevant diseases. Chin Pharmacol Bull 2016;32(12):1634-8.

15. $\mathrm{Hu}$ J, Yang L. Pregabalin in the treatment of postherpetic neuralgia. J Clin Dermatol 2013;42(2):126-127.

16. Wu CY. Effect of pregabalin combined with laser on postherpetic neuralgia. Friends Health 2021;(12):144.

17. Li JX, Tang QQ, Liu D, Long J, Liu X, Duan RG, et al. Therapeutic effect of gabapentin and pregabalin on postherpetic neuralgia. Pract J Clin Med 2012;9(4):150-2.

18. Derry S, Bell RF, Straube S, Wiffen PJ, Aldington D, Moore RA. Pregabalin for neuropathic pain in adults. Cochrane Database Syst Rev 2019(1).

19. Sałat K, Librowski T, Nawiesniak B, Gluch-Lutwin M. Evaluation of analgesic, antioxidant, cytotoxic and metabolic effects of pregabalin for the use in neuropathic pain. Neurol Res 2013;35(9):948-58.

20. Roy Freeman BE, Parsons B. Predictors of placebo response in peripheral neuropathic pain: Insights from pregabalin clinical trials. J Pain Res 2015;8:257-68.

21. Xue Q, Ding H, Zhang J, Zhao J. Efficacy analysis of pregabalin combined with $5 \%$ lidocaine gel plaster in the treatment of postherpetic neuralgia. Med Aesthet Cosmetol 2021;30(12):101-2.

This is an open access article distributed under the terms of the Creative Commons Attribution-NonCommercial-ShareAlike 3.0 License, which allows others to remix, tweak, and build upon the work non-commercially, as long as the author is credited and the new creations are licensed under the identical terms

This article was originally published in a special issue, "Novel Therapeutic Approaches in Biomedicine and Pharmaceutical Sciences" Indian J Pharm Sci 2021:83(6) Spl Issue "164-168" 